\title{
Correction to: Comparison of storability and seasonal changes on new flavonoids, polyphenolic acids and terepene compounds of Citrus paradisi (grapefruit) cv. shamber through advance methods
}

\author{
Wassem Ahmed ${ }^{1}$ (D) Rafa Azmat ${ }^{2} \cdot$ Ayaz Mehmood $^{3} \cdot$ Rasheed Ahmed $^{3} \cdot$ M. Liaquat $^{5} \cdot$ Sami Ullah Khan ${ }^{4}$. \\ Abdul Qayyum $^{4}$. Shah Masauad Khan ${ }^{1}$
}

Published online: 20 May 2021

(c) Springer Science+Business Media, LLC, part of Springer Nature 2021

\section{Correction to: \\ Journal of Food Measurement and Characterization https://doi.org/10.1007/s11694-021-00815-y}

The original version of this article unfortunately contained a mistake. The co-author name Rafa Azmant was incorrect.

The correct name should be Rafa Azmat.

The original article has been corrected.

Publisher's Note Springer Nature remains neutral with regard to jurisdictional claims in published maps and institutional affiliations.

The original article can be found online at https://doi.org/10.1007/ s11694-021-00815-y.

\section{Wassem Ahmed}

waseemuaf12@gmail.com

1 Department of Horticulture, The University of Haripur, Haripur, Pakistan

2 Department of Chemistry, University of Karachi, Karachi, Pakistan

3 Department of Soil Science, The University of Haripur, Haripur, Pakistan

4 Department of Agronomy, The University of Haripur, Haripur, Pakistan

5 Department of Food Science and Technology, The University of Haripur, Haripur, Pakistan 